\title{
Neovascularization of ischemic tissues by gene delivery of the extracellular matrix protein Del-1
}

\author{
Jingping Zhong, ${ }^{1}$ Brian Eliceiri, ${ }^{2}$ Dwayne Stupack, ${ }^{2}$ Kalyani Penta, ${ }^{3}$ Gordon Sakamoto, ${ }^{3}$ \\ Thomas Quertermous, ${ }^{3}$ Mike Coleman, ${ }^{4}$ Nancy Boudreau, ${ }^{5}$ and Judith A. Varner ${ }^{1}$ \\ ${ }^{1}$ Department of Medicine and Comprehensive Cancer Center, University of California, San Diego, La Jolla, California, USA \\ ${ }^{2}$ Department of Immunology, Scripps Research Institute, La Jolla, California, USA \\ ${ }^{3}$ Donald W. Reynolds Cardiovascular Clinical Research Center, Stanford University, Palo Alto, California, USA \\ ${ }^{4}$ Valentis Inc., Burlingame, California, USA \\ ${ }^{5}$ Surgical Research Laboratories, University of California, San Francisco, San Francisco, California, USA
}

\begin{abstract}
The ECM protein Del-1 is one of several novel ECM proteins that accumulate around angiogenic blood vessels in embryonic and tumor tissue and promote angiogenesis in the absence of exogenous growth factors. Del-1 expressed in mouse or rabbit ischemic hind-limb muscle by gene transfer rapidly promotes new blood vessel formation and restores muscle function. This angiogenic ECM protein initiates angiogenesis by binding to integrin $\alpha v \beta 5$ on resting endothelium, thereby resulting in expression of the transcription factor Hox D3 and integrin $\alpha v \beta 3$. Hox D3 converts resting endothelium to angiogenic endothelium by inducing expression of proangiogenic molecules such as integrin $\alpha v \beta 3$. These findings provide evidence for an angiogenic switch that can be initiated in the absence of exogenous growth factors and indicate that the angiogenic matrix protein Del-1 may be a useful tool for the therapy of ischemic disease.
\end{abstract}

J. Clin. Invest. 112:30-41 (2003). doi:10.1172/JCI200317034.

\section{Introduction}

The development of new blood vessels from an existing network of vessels, angiogenesis, occurs during embryonic development, cancer, and arthritis and in response to ischemia (1-7). Novel angiogenesis-inducing therapies have been developed recently to stimulate collateral vessel formation and to improve muscle function in the treatment of occlusive vascular disease, such as myocardial and limb ischemia (5-7).

Angiogenesis requires signals that are transduced from growth factor receptors and integrins (1-4). Soluble growth factors initiate angiogenesis, whereas integrins promote endothelial cell (EC) survival and migration (1-4). Recent studies, however, have identified an alternative mechanism for angiogenesis induction. Several proangiogenic ECM proteins (Del-1, Cyr 61, Nov, connective tissue growth factor/Fisp12, and others) are found in association with vascular endothelium and

Received for publication October 1, 2002, and accepted in revised form April 29, 2003.

Address correspondence to: Judith A. Varner, Comprehensive Cancer Center, University of California, San Diego, 9500 Gilman Drive, La Jolla, California 92093-0912, USA.

Phone: (858) 822-0086; Fax: (858) 822-1325;

E-mail: jvarner@ucsd.edu.

Conflict of interest: Mike Coleman is an employee of Valentis Inc. Thomas Quertermous is the inventor of Del-1, which is licensed to Valentis Inc. and for which he receives licensing fees.

Nonstandard abbreviations used: endothelial cell (EC); arginineglycine-aspartic acid (RGD); human VEGF ${ }_{165}\left(\right.$ hVEGF $\left._{165}\right)$; human Del-1 (hDel-1); chorioallantoic membrane (CAM); avian retrovirus expressing human Hox D3 (CK-D3); CK virus without the insert (CK); green fluorescent protein (GFP); human umbilical vein EC (HUVEC); human microvascular EC (HMVEC). promote $\alpha v \beta 3$ integrin-dependent angiogenesis in the absence of exogenously added growth factors (8-13). One of these "angiomatrix" proteins, Del-1, is a 52-kDa protein that contains three Notch-like EGF domains, an arginine-glycine-aspartic acid (RGD) motif, and two F5/F8 C-terminal domains (13), such as are found in discoidin and factor VIII.

Del-1 promotes EC migration and angiogenesis that is blocked by antagonists of integrin $\alpha v \beta 3$ (11). It is unclear how Del-1 or any of the other angiomatrix proteins induce angiogenesis, however, since their known receptor, integrin $\alpha v \beta 3$, is poorly expressed on resting ECs and requires prior EC activation $(14,15)$. Clearly, alternative receptors for Del-1 must exist on ECs. In this report, we evaluate the potential of Del-1 to stimulate therapeutic angiogenesis, and we investigate the mechanisms by which it initiates angiogenesis. We demonstrate that integrin $\alpha v \beta 5$ serves as a receptor for Del-1, thereby promoting cell migration and survival. Furthermore, ligation of EC integrin $\alpha v \beta 5$ is required for the initiation of angiogenesis by Del-1. Ultimately, Del-1- $\alpha v \beta 5$ interactions induce $\alpha v \beta 3$ expression and angiogenesis.

\section{Methods}

Murine angiogenesis assays. C57BL/6J wild-type and C57BL/6 $\times 129$ SF2/J wild-type mice were purchased from The Jackson Laboratories (Bar Harbor, Maine, USA). C57BL $/ 6 \mathrm{~J} 35^{-/-}$and age-matched sibling $\beta 5^{+/-}$ mice (16) were obtained from Dean Sheppard (University of California, San Francisco). Integrin $\beta 3^{-/-}$mice (a kind gift of Richard Hynes, Massachusetts Institute of Technology, Cambridge, Massachusetts, USA) were on a C57BL/6 $\times 129 \mathrm{SF} 2 / \mathrm{J}$ background. Angiogenesis 
assays were performed as described (17) by injecting subcutaneously $400 \mu \mathrm{l}$ of $1 \mu \mathrm{g} / \mathrm{ml}$ bFGF or $400 \mu \mathrm{l}$ of $100 \mu \mathrm{g} / \mathrm{ml}$ Del-1 in growth factor-reduced Matrigel. Ten $\beta 5^{-/-}$, five $\beta 5^{+/+}$, and three $\beta 5^{+/-}$mice were stimulated with bFGF, and the same numbers were stimulated with Del-1. Eleven $\beta 3^{-/}$, six C57BL $/ 6 \times 129 \mathrm{SF} 2 / \mathrm{J}$ $\left(\mathrm{F}_{2}\right.$ hybrid) $\beta 3^{+/+}$, and seven $\mathrm{C} 57 \mathrm{BL} / 6 \mathrm{~J}$ wild-type mice were stimulated with $\mathrm{bFGF}$, and the same numbers were stimulated with Del-1 in two separate experiments. After 7 days, Matrigel plugs were excised, embedded in OCT, frozen, and sectioned. Thin sections $(5 \mu \mathrm{m})$ were immunostained with rat anti-murine CD31 and with Alexa 568-conjugated goat anti-rat Ig. CD31-positive vessel density per $\times 200$ microscopic field was determined in five fields per Matrigel plug. Mouse hind-limb ischemia model. Purified plasmids consisting of a CMV enhancer/promoter, $5^{\prime}$ UTR, an optimized intron, $c D N A$ encoding either human $V_{E G F}$ $\left(\mathrm{hVEGF}_{165}\right)$ or full-length human Del-1 (hDel-1), and the hGH 3' UTR, as well as a kanamycin resistance gene, were formulated at a concentration of $1 \mathrm{mg} / \mathrm{ml}$ with nonionic polymer poloxamer 188 at an optimized concentration of $5 \%(\mathrm{wt} / \mathrm{vol})(18,19)$. CD-1 male mice were sedated with ketamine $(7.4 \mathrm{mg} / \mathrm{g})$, xylazine $(0.4$ $\mathrm{mg} / \mathrm{g})$, and acepromezine $(0.08 \mathrm{mg} / \mathrm{g})$. A longitudinal incision was made on the medial side of the thigh inferior to the inguinal ligament to a point proximal of the patella. Both femoral arteries were ligated at their proximal origins from the iliac artery and distally at the bifurcation into the popliteal and saphenous arteries. Plasmids were formulated with the nonionic polymer poloxamer 188 at an optimized concentration of 1 $\mathrm{mg} / \mathrm{ml}$ plasmid with $5 \% \mathrm{wt} / \mathrm{vol}$ poloxamer $(18,19)$. Formulated plasmids were injected into seven sites (10 $\mu \mathrm{g} / \mathrm{site}$ ) of each hind limb (for all treatment groups). Mice were injected intramuscularly with no insert control, $b V E G F$ or $b D e l-1$ plasmids ( $n=7-8$ per treatment). After 1 week, animals were placed on a treadmill at a 7 -degree angle for 5 minutes at $5 \mathrm{~m} / \mathrm{min}$ to acclimate, and then speed was increased to $10 \mathrm{~m} / \mathrm{min}(t=0)$. Speed was increased every 2 minutes until fatigue (when animals spent more than 5 seconds on the stimulator grid at the rear of the treadmill). Results represent mean plus or minus SEM treadmill run time. Statistical analysis was performed by repeated measures ANOVA. Cryosections $(5 \mu \mathrm{m})$ of injected tibialis muscle were immunostained with rat anti-Del-1 or rat antimurine CD31 (PharMingen, San Diego, California, USA). Paraffin sections $(3 \mu \mathrm{m})$ were immunostained with rabbit anti-VEGF 165 (Intergen Co., Purchase, New York, USA) after blocking with normal serum. Sections were then incubated with biotinylated secondary Ab's followed by avidin-HRP (Vector Laboratories, Burlingame, California, USA). Immune complexes were detected with 3,3-diaminobenzidine (Vector Laboratories). Optimas image analysis software was used to determine capillary/myofiber ratio in five randomly selected microscopic fields per mouse. Differences between treatment groups were determined by
ANOVA, followed by the Duncan test when the main effect was significant $(P<0.05)$.

Rabbit hind-limb ischemia model. Unilateral hind-limb ischemia was induced in New Zealand white rabbits (3-4 kg body weight) by surgical resection of the femoral artery as described (20). Angiography was performed immediately following surgery. Three to 4 days after surgical resection of the femoral artery, formulated noncoding $(n=3), b V E G F_{165}(n=6)$, or $b$ Del- $1(n=4)$ plasmid was injected at ten sites $(0.5 \mathrm{mg} / \mathrm{site})$ in the upper leg. The amount of plasmid injected per site was based on results from a dose-optimization study in rabbits. Results from this study demonstrated that dividing the total dose of plasmid among a greater number of sites yielded higher and more uniform transgene expression within the treated muscle. To assess the effects of angiogenic gene therapy on formation of collateral vessels, serial angiography was performed immediately after surgical resection of the femoral artery and again at 4 weeks after gene transfer in the rabbit model. To quantify the number of visible collateral vessels, still images were captured at a constant frame number following appearance of contrast media at the femoral head. Visible collateral arteries crossing the midthigh were counted by two observers blinded to treatment before treatment and again 4 weeks after treatment. The number of new collateral vessels present at 4 weeks was then calculated for each animal by subtraction of the baseline value. Treatment effects were analyzed by one-way ANOVA using the Duncan test to compare individual means when the main effect of treatment was significant. Animals were sacrificed, and samples of treated muscle were harvested for analysis of transgene and CD31 expression. The bVEGF 165 and $h D e l-1$ transgene expressions were assessed in $1-\mathrm{cm}^{3}$ samples of muscle tissue by RT-PCR. The $5^{\prime}$ primer for $D e l-1$ was 5'-TGACCTCCATAGAAGACACCGGGAC-3'. The 3' primer for $D e l-1$ was $5^{\prime}$-CTGATGCAACCTCCACAACACTAGA- $3^{\prime}$. The $5^{\prime}$ primer for $V E G F$ is $5^{\prime}$-TGACCTCCATAGAAGACACCGGGAC- $3^{\prime}$. The $3^{\prime}$ primer for $V E G F$ is $5^{\prime}$-GGAGGGGTCACAGGGATGC- $3^{\prime}$. The $5^{\prime}$ primer is the same for both transgenes because it is in the $5^{\prime}$ UTR of the expression cassette. These primer pairs will not amplify endogenous Del-1 or VEGF genes. CD31 levels within injected muscle were assessed by Western blot analysis. Results for angiography and CD31 analyses were assessed by one-way ANOVA with plasmid treatment as the main effect.

Ligand-binding assays. Integrin $\alpha v \beta 3$ and $\alpha 5 \beta 1$ receptors were purified from human placenta by immunoaffinity chromatography. Integrin $\alpha v \beta 5$ was immunoaffinity purified from $\alpha v \beta 5$-transfected tumor cells. Each integrin was characterized by silver staining after gel electrophoresis and found to be more than $95 \%$ pure. Recombinant murine Del-1 (11), collagen (Collaborative Biomedical Products, Bedford, Massachusetts, USA), vitronectin (21), and the $120-\mathrm{kDa}$ fibronectin fragment (Chemicon International, Temecula, California, USA) were biotinylated, and ligand-binding 


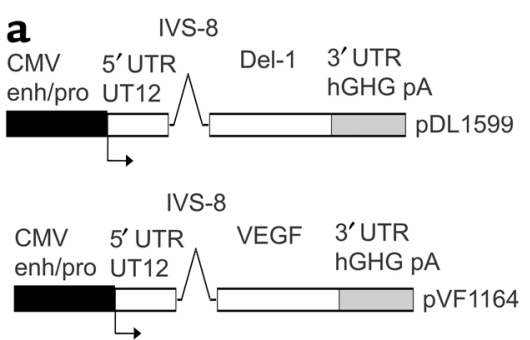

e

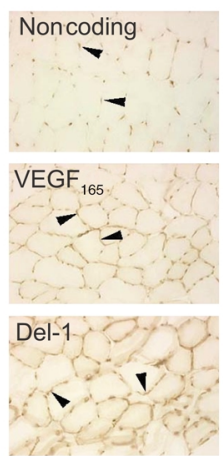

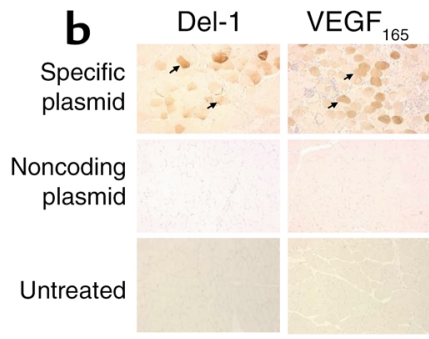

C

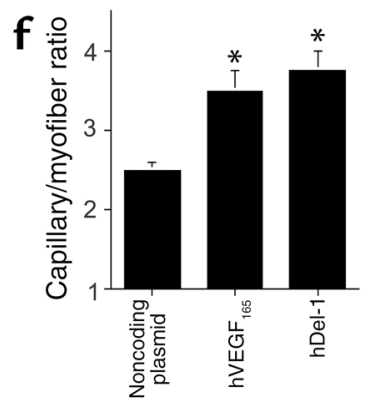

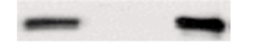

Del-1 Cntl pur.Del-1 g

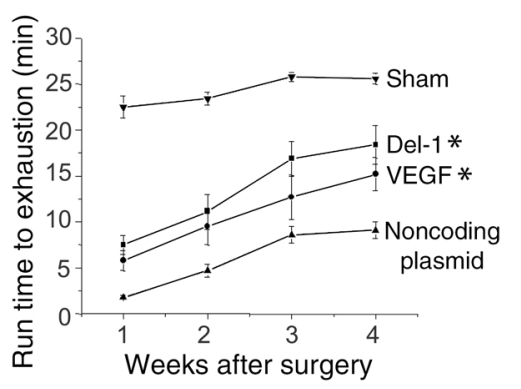

Figure 1

Del-1 promotes angiogenesis and restores function to murine ischemic muscle in vivo. (a) Expression constructs used to induce hDel-1 and hVEGF expression in vivo contained a CMV enhancer/promoter (enh/pro), $5^{\prime}$ UTR, an optimized intron (IVS-8), cDNA encoding either $V E G F_{165}$ (pVF1164) or full-length human Del-1 (pDL1599), and the hGH 3' UTR, as well as a kanamycin resistance gene. (b) Expression of Del-1 or VEGF 165 in hDel-1 (left) and $h V E G F_{165}$ (right) transgene-injected, noncoding plasmid-injected, and untreated muscle. Photographs were taken at $\times 100$ magnification. Arrows denote fibers exhibiting positive staining. Cntl, control. (c) Lysates of muscle injected with $h D e l-1$ (Del-1) or noncoding control plasmid as well as purified Del-1 (pur.Del-1) were immunoblotted for Del-1 expression using rabbit anti-Del-1 Ab's. (d) Mouse model of hind-limb ischemia induced by ligation of the femoral artery. (e and $\mathbf{f}$ ) Capillary/myofiber ratio 7 days after treatment with noncoding (control), $h D e l-1$, or $h V E G F_{165}$ expression plasmids. (e) Cryosections of treated muscle immunostained using a rat antimouse CD31 Ab. (f) Mean capillary/myofiber ratio \pm SEM for three animals per group $\left({ }^{*} P<0.01\right)$. (g) Hind-limb ischemia was induced by bilateral ligation of the femoral artery of male CD1 mice. Animals were placed on the treadmill for 5 minutes at $5 \mathrm{~m} / \mathrm{min}$ and then at 10 $\mathrm{m} / \mathrm{min}$ thereafter. The speed was increased every 2 minutes until fatigue. Results represent the mean \pm SEM $(n=7-8$ animals/group) treadmill run time for mice treated with formulated noncoding $h D e l-1$ or $h V E G F_{165}$ expression plasmids. Asterisks indicate statistically significant result relative to noncoding plasmid control $(P<0.05)$.

assays were performed as described $(22,23)$. Experiments were performed three times.

Chicken chorioallantoic membrane assays. Chicken embryos (McIntyre Poultry, Ramona, California, USA) were stimulated with $3 \mu \mathrm{g}$ recombinant murine Del-1, 30 ng recombinant human bFGF or human VEGF (Genzyme Pharmaceuticals, Cambridge, Massachusetts, USA), or $30 \mu \mathrm{l}$ saline as described (22). Ten micrograms anti- $\alpha v \beta 3$ (LM609), anti- $\alpha v \beta 5$ (P1F6), control Ab's (W6/32), or saline were applied to chicken chorioallantoic membranes (CAMs) at 0,24 , or 48 hours. CAMs were stimulated with $10^{7} \mathrm{PFU}$ of adenoviruses expressing murine Del-1 or $\beta$-galactosidase (LacZ) or with $10^{6}$ PFU CK-D3-transfected (avian retrovirus expressing human Hox D3) (24) or CK virus-transfected (without insert) quail fibrosarcoma cells (24) for 72 hours. In other studies, $2 \mu \mathrm{g}$ purified plasmid DNA of $p C H G$ (Hox D3 sense) (24) or $p C M V-D 3 A S$ (Hox D3 antisense) (24) and/or $2 \mu$ g green fluorescent protein plasmid (N1-GFP) were applied to Del-1- or bFGF-stimulated CAMs. Paraformaldehyde (500 $\mu \mathrm{l} ; 3.7 \%)$ was applied to CAMs prior to excision for counting vessel branch points (22).
Unfixed CAMs were flash-frozen, sectioned, and stained with anti-integrin and vWF Ab's or homogenized in icecold RIPA buffer prior to analysis of protein expression for integrins $\alpha v \beta 3$ and $\alpha v \beta 5$ (17). Ten embryos were used per treatment group. Statistical analyses were performed using a Student $t$ test.

In vitro cell culture. ECs were cultured in EGM, a complete growth medium containing bFGF, VEGF, and serum from Clonetics Corp. (San Diego, California, USA). Endothelial quiescence was induced by culturing human umbilical vein ECs (HUVECs) on 1-mm-thick layers of basement membrane (growth factor-reduced Matrigel) or gelatin in EGM. In some studies, the EGM was supplemented with $10 \mu \mathrm{g} / \mathrm{ml}$ Del-1 with or without $25 \mu \mathrm{g} / \mathrm{ml} \mathrm{P} 1 \mathrm{~F} 6$ or W6/32 for 24 hours. Cell lysates were prepared as described (25).

PCR. RNA was extracted from CAMs or cells using QIAGEN Inc. (Valencia, California, USA) RNeasy kits. The cDNA primers for $b G A D P H$ and $b H o x D 3$ were described previously (24). Others were $h \beta 3 F\left(5^{\prime}\right.$-СCTCTGTGGTCAATGTGTCTGC-3'), $h \beta 3 R\left(5^{\prime}\right.$-TTCTTTTCGGTCGTGGATGGTG-3'), $h \beta 5 F$ (5'-CTGCTAATCCACCCAA- 
AATG-3'), $h \beta 5 R \quad\left(5^{\prime}\right.$-AAAAGACCCAAATCCCAACC-3'), ckGADPH-F (5'-CTACACACGGACACTTCAAGGGCA-3'), ckGADPH-R (5'-TCCAGACGGCAGGTCAGGTCAACA-3'), $c k H o \times D 3-F\left(5^{\prime}\right.$-AAAGAGATACACGGGGACAGCA-3'), and ckHoxD3-R ( $5^{\prime}$-AGAGATGAGTTAGACCAAAGAT-3'). Products were $h G A D P H$ (600 bp), hHox D3 (415 bp), $\beta 3$ (676 bp), $\beta 5$ (426 bp), ckGADPH (598 bp), and ckGADPH (170 $\mathrm{bp})$. Experiments were performed three to five times.

\section{Results}

Del-1 promotes angiogenesis and functional recovery in models of bind-limb ischemia. The proangiogenic ECM protein Del-1 is expressed by ECs during embryonic and tumor development (11-13). Del-1 promotes angiogenesis in chick, murine, and human in vivo models of angiogenesis $(11,12)$. In contrast, ECM proteins such as fibronectin, fibrinogen, vitronectin, and collagen are unable to induce angiogenesis (11).

To evaluate the potential of human Del-1 to induce neovessels in ischemic tissues, we induced sustained expression of human Del-1 as well as human VEGF 165 in mouse tibialis muscle by injection of hDel-1 and hVEGF encoding expression plasmids (Figure 1a). Injection of reporter gene constructs encoding GFP and luciferase demonstrated that optimal expression could be achieved with this plasmid formulation injected at multiple sites in tibialis muscle $(18,19)$. In vivo expression of $h D e l-1$ and $h V E G F_{165}$ was readily detected in treated murine tibalis anterior muscles, but not in untreated or control-transfected muscle, by immunohistochemical analysis 7 days after injection of formulated plasmid (Figure 1b). Arrows denote fibers that exhibit positive staining. Similar results were obtained in Western blot analysis of muscle lysates (Figure 1c) and RT-PCR studies (data not shown). The Del-1 and VEGF detected was due to induced expression of human genes, since no expression of Del-1 or VEGF was detected in control-transfected tissues. Thus, these studies indicate that gene transfer leads to significant induction of human Del-1 expression in vivo.
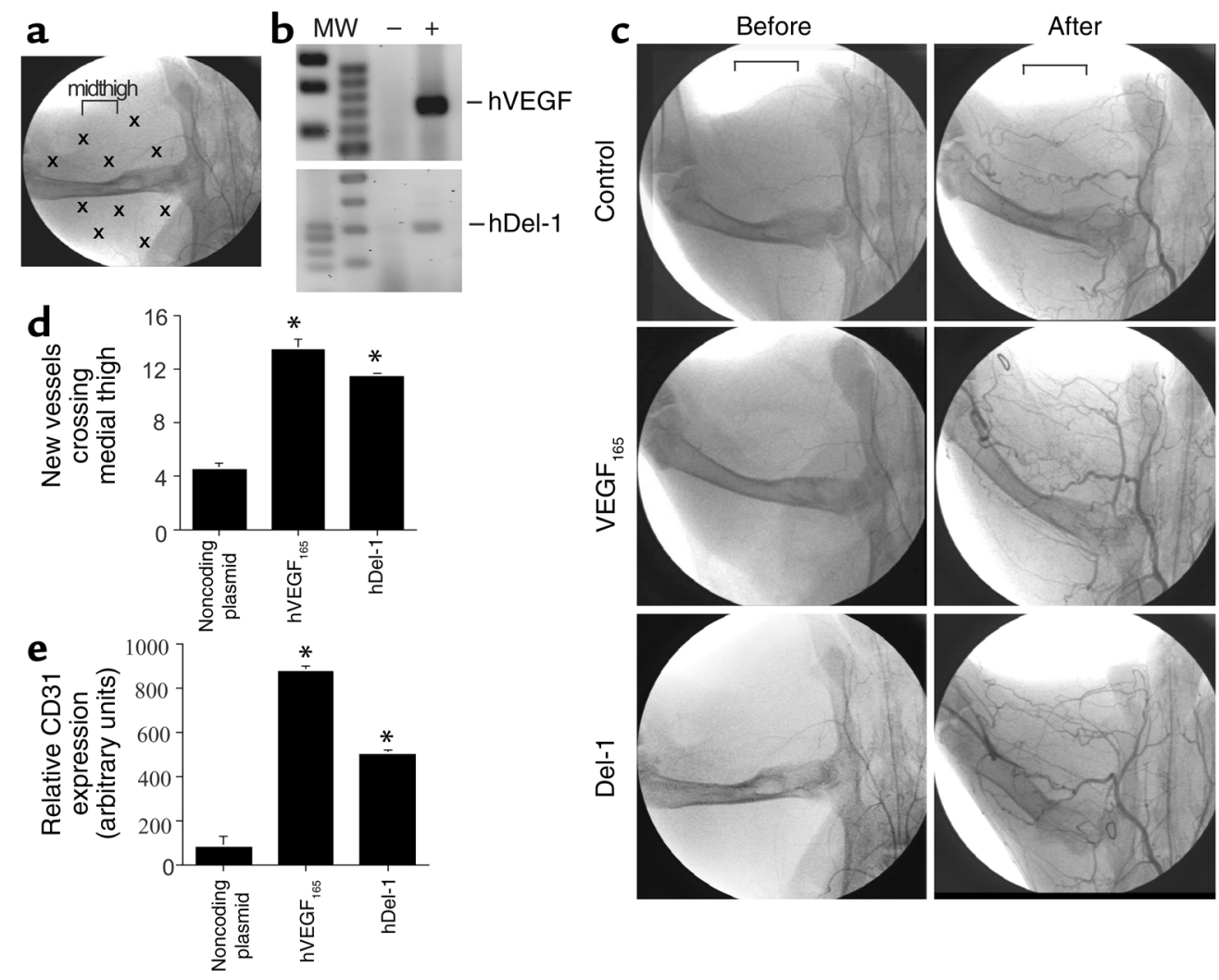

\section{Figure 2}

Del-1 induces angiogenesis in rabbit model of ischemia. (a) Angiography was performed after unilateral hind-limb ischemia induced in New Zealand white rabbits (3-4 kg body weight) by surgical resection of the femoral artery (19). X's indicate the ten sites in and surrounding the medial thigh (midthigh) (bracket) in the upper leg, where plasmid was injected $(0.5 \mathrm{mg} / \mathrm{site})$. (b) Sustained transgene expression induced by plasmid injection in muscle was detected 1 month after therapy by RT-PCR for hVEGF 165 and hDel-1. VEGF or Del-1 gene expression was detected in VEGF- or Del-1-plasmid-injected muscle, respectively, but not in control plasmid-injected muscle. MW, molecular weight standards. (c) Angiography was performed before and 1 month after therapy for each treatment. Brackets indicate medial thigh region. (d) Mean number of new vessels $( \pm S D)$ crossing the medial thigh (area under the brackets in c) for each treatment 1 month after therapy. Asterisks indicate statistically significant result $(P<0.01)$. (e) Mean CD31 protein expression $( \pm$ SD) in muscle tissue 1 month after therapy. CD31 levels within injected muscle were assessed by Western blot analysis of lysates of muscle tissue. Asterisks indicate statistically significant result relative to noncoding plasmid control $(P<0.01)$. Statistical significance for angiography and CD31 analyses was assessed by one-way ANOVA with plasmid treatment as the main effect. 
a
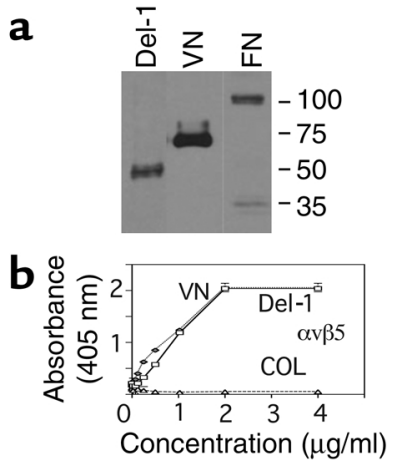

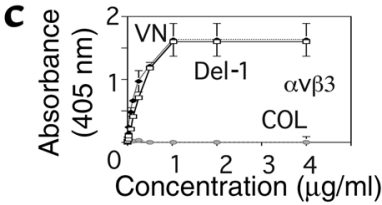

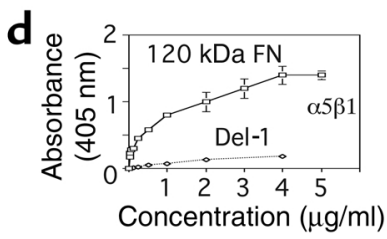

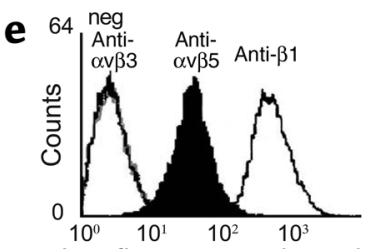

g Log fluorescence intensity

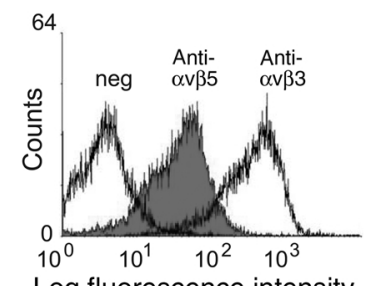

Log fluorescence intensity

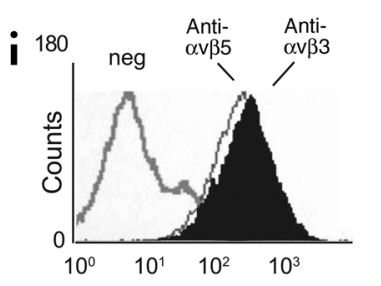

Log fluorescence intensity
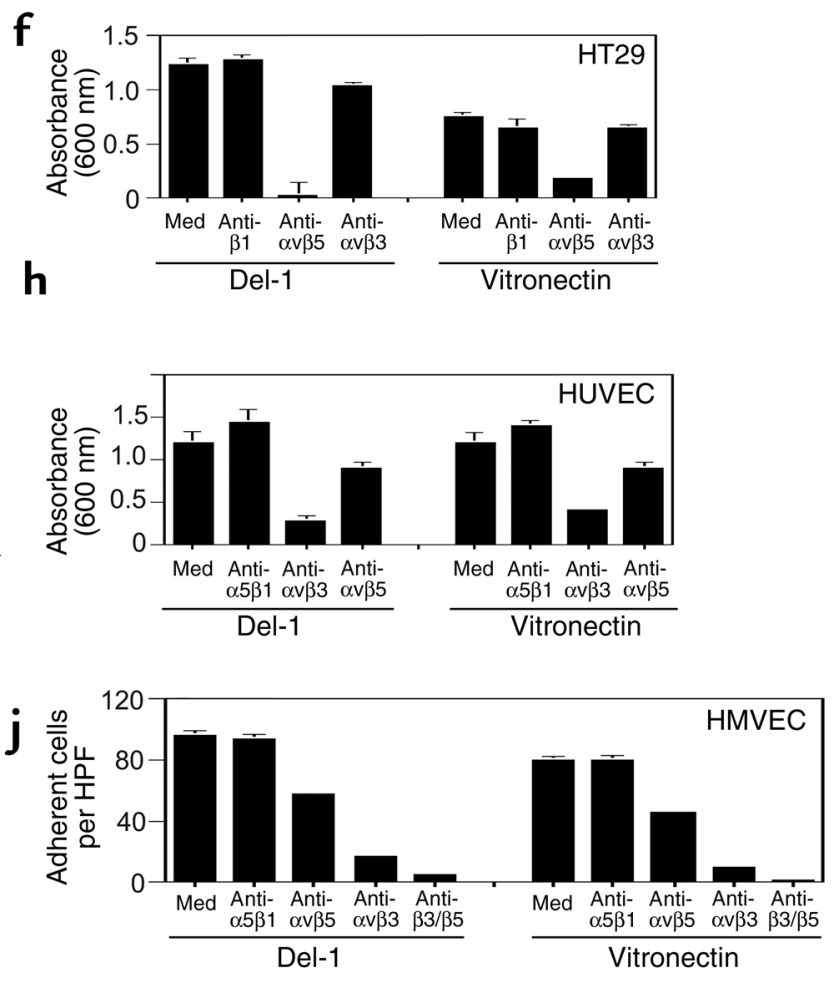

\section{Figure 3}

Integrin $\alpha v \beta 5$ is a receptor for Del-1. (a) Biotinylated Del-1 (Del-1), vitronectin (VN), or the 120-kDa cell-binding fragment of fibronectin (FN) immunoblotted with goat-antibiotin HRP. (b-d) Biotinylated Del-1, vitronectin, collagen (COL), or biotinylated 120-kDa cell-binding region of fibronectin incubated with purified integrins $\alpha v \beta 5$ (b), $\alpha v \beta 3$ (c), or $\alpha 5 \beta 1$ (d) were quantified by determining absorbance at $405 \mathrm{~nm}$. (e) FACS profile of HT29 colon carcinoma cells incubated with anti- $\alpha v \beta 5$, anti- $\alpha v \beta 3$, anti- $\beta 1$, or no primary Ab (neg) followed by FITC-labeled secondary Ab. Data are plotted as log of fluorescence intensity versus cell number times $10^{-5}$. (f) The adhesion of integrin $\alpha v \beta 5$-positive/ $\alpha v \beta 3$ negative HT29 colon carcinoma cells to Del-1 or vitronectin in the presence of culture medium (med), function-blocking anti-integrin Ab's anti- $\alpha v \beta 3$, anti- $\alpha v \beta 5$, or anti-integrin $\beta 1$. (g) FACS profile of HUVECs incubated with anti- $\alpha v \beta 5$, anti- $\alpha v \beta 3$, or no primary Ab (neg) followed by FITC-labeled secondary Ab, as in e. (h) The adhesion of $\alpha v \beta 5$-positive/ $\alpha v \beta 3$-positive HUVECs on Del-1 or vitronectin in the presence of culture medium, function-blocking anti-integrin $A b$ 's anti- $\alpha v \beta 3$, anti- $\alpha v \beta 5$, or anti-integrin $\alpha 5 \beta 1$. (i) FACS profile of human microvascular endothelial cells (HMVECs) incubated with anti- $\alpha v \beta 5$, anti- $\alpha v \beta 3$, or no primary $A b$ (neg), followed by FITC-labeled secondary Ab, as in e. (j) The adhesion of quiescent HMVECs on Del-1 or vitronectin in the presence of culture medium, function-blocking anti-integrin Ab's anti- $\alpha v \beta 3$, anti- $\alpha v \beta 5$, anti-integrin $\alpha 5 \beta 1$, or anti- $\alpha v \beta 3$ combined with anti- $\alpha v \beta 5$ (anti- $\beta 3 / \beta 5$ ). HPF, high-power field. Magnification, $\times 200$.

When tested in a mouse model of hind-limb ischemia (Figure 1d), intramuscular injections of formulated $b V E G F$ and $b D e l-1$ plasmids were equally effective in inducing neovessels (Figure 1, e and $\mathrm{f}$ ) and in restoring hind-limb function (Figure 1g). Injection of $b V E G F$ - or bDel-1-encoding plasmids, but not noncoding plasmid, induced the growth of CD31-positive neovessels in transfected muscle (Figure 1e). Capillary/myofiber ratios in both $b V E G F$ - and $h D e l-1$-treated muscle were approximately 1.7 -fold greater $(P<0.01)$ than in control-treated muscle (Figure 1e). Bilateral ligation of the femoral artery in CD-1 male mice dramatically inhibited mouse performance in a treadmill stress test $(P<0.05)$. Expression of either Del-1 $(P<0.05)$ or VEGF $(P<0.05)$ significantly increased muscle function and performance in the treadmill test, with improved performance lasting over 4 weeks (Figure 1f). These studies indicate that the Del-1 protein can be expressed through gene transfer in vivo and that Del-1 can induce angiogenesis and improve function in murine ischemic muscle.
To determine whether Del-1 promotes angiogenesis and recovery in larger animal models of ischemia, formulated, noncoding $b V E G F_{165}$ or $h D e l-1$ plasmids were injected into ischemic rabbit hind limbs. Unilateral hind-limb ischemia was induced in New Zealand white rabbits by surgical resection of the femoral artery (20). Pilot expression studies using reporter genes (GFP and luciferase) demonstrated that optimal expression could be achieved in the rabbit muscle with the plasmid formulation injected at ten different sites surrounding the medial thigh (Figure 2a). Injection of $b V E G F$ and $h D e l-1$ plasmids resulted in in vivo expression of the transgenes (Figure 2, a and b) and induced the formation of new collateral vessels that cross the medial thigh (Figure 2c). Expression of VEGF or Del-1 genes could be detected in random samplings of injected, but not noninjected, muscle tissues across the medial thigh (Figure $2 \mathrm{~b})$. Both $h V E G F$ and $b D e l-1$ induced the formation of threefold more new blood vessels crossing the medial thigh than did noncoding plasmid $(P<0.01)$ (Figure 2, 
$c$ and d). A similar index of new blood vessel induction by $h V E G F$ and $b D e l-1$ was indicated by quantification of CD31 expression levels in muscle lysates by immunoblotting $(P<0.01)$ (Figure $2 \mathrm{e})$. Therefore, in rabbit and murine models of hind-limb ischemia, Del-1 is potent angiogenic factor. Thus, Del-1 is a useful stimulator of in vivo angiogenesis with potential therapeutic value for ischemic disease.

Integrin $\alpha \nu \beta 5$ is a receptor for Del-1. Since Del-1 and other angiomatrix proteins are potent proangiogenic factors, it is important to understand the mechanisms by which these proteins induce angiogenesis to enable greater control over their roles in pathological or therapeutic angiogenesis. It is unclear how Del-1, or other angiomatrix proteins, initiates angiogenesis, because integrin $\alpha v \beta 3$, a known receptor for Del-1, is poorly expressed on quiescent vascular endothelium and is expressed at high levels only after growth-factor stimulation of endothelium (15). To determine if integrins that are expressed on quiescent endothelium, such as $\alpha v \beta 5$, can function as receptors for Del-1, we incubated purified integrins plated on microtiter plates with dilutions of purified, biotinylated Del-1 (Figure 3a). Biotinylated, purified Del-1 bound with strong avidity to both purified integrins $\alpha v \beta 3$ (Figure $3 \mathrm{~b}$ ) and $\alpha v \beta 5$ (Figure 3c) in these in vitro ligand-binding assays, as did biotinylated vitronectin. In contrast, biotinylated collagen did not bind to either of these integrins (Figure 3b). RGD, but not RGE, peptides and EDTA blocked Del-1 binding to both integrins (not shown). Del-1 does not bind purified integrin $\alpha 5 \beta 1$, another integrin that plays a role in angiogenesis (17). A $120-k D a$ fragment of purified fibronectin does bind $\alpha 5 \beta 1$ in a saturable manner in this assay (Figure $3 \mathrm{~d}$ ). Thus, Del-1 is a ligand for integrin $\alpha v \beta 5$ as well as for $\alpha v \beta 3$, but not for $\alpha 5 \beta 1$.

To determine whether Del-1 serves as an adhesive ligand for cellular $\alpha v \beta 5$, we examined the interaction of Del- 1 and $\alpha v \beta 5$ in colon carcinoma and ECs. HT29 colon carcinoma cells expressing $\alpha v \beta 5$ but not $\alpha v \beta 3$

\section{Figure 4}

Del- 1 interactions with $\alpha v \beta 5$ regulate integrin $\alpha v \beta 3$ expression. (a and $\mathbf{b}$ ) Cryosections of CAMs stimulated with Del-1 were incubated with Ab's against integrin $\alpha v \beta 3$ or $\alpha v \beta 5$ in combination with Ab's against vWF. Integrin expression was detected with a rhodamine-conjugated secondary $A b$ and vWF with an FITC-conjugated secondary Ab. Integrin expression on blood vessels is seen as orange-yellow structures. Representative sections were photographed at $\times 200$. White bar indicates $10 \mu \mathrm{m}$. (b) Average integrin expression levels for each integrin in vessels were quantified by determining the average number of red pixels in vessels that was greater than background and dividing by the average number of green pixels greater than background. (c) Integrins $\alpha v \beta 3$ and $\alpha v \beta 5$ were immunoprecipitated from lysate CAMs stimulated with bFGF or Del-1. Immunoprecipitates were immunoblotted with Ab's against the cytoplasmic tails of the $\beta 3$ and $\beta 5$ subunits. Ratios of $\alpha v \beta 3$ to $\alpha v \beta 5$ were determined by densitometry. (d) CAMs were stimulated with Del-1 in the presence or absence of saline, anti- $\alpha v \beta 5$, or W6/32 control isotype-matched Ab's. Cryosections of CAMs were then incubated in anti- $\alpha v \beta 3$ and anti-vWF Ab's. Integrin $\alpha v \beta 3$ expression was detected with a rhodamine-conjugated secondary $\mathrm{Ab}$ and vWF with an FITC-conjugated secondary Ab. Representative sections were photographed at $\times 200$. White bar indicates $10 \mu \mathrm{m}$. Integrin $\alpha v \beta 3$ expression on blood vessels is seen in yellow. Blood vessels are indicated with arrows. clgG, control IgG. (e) Expression levels of integrin $\alpha v \beta 3$ in vessels were quantified as in $\mathbf{b}$.
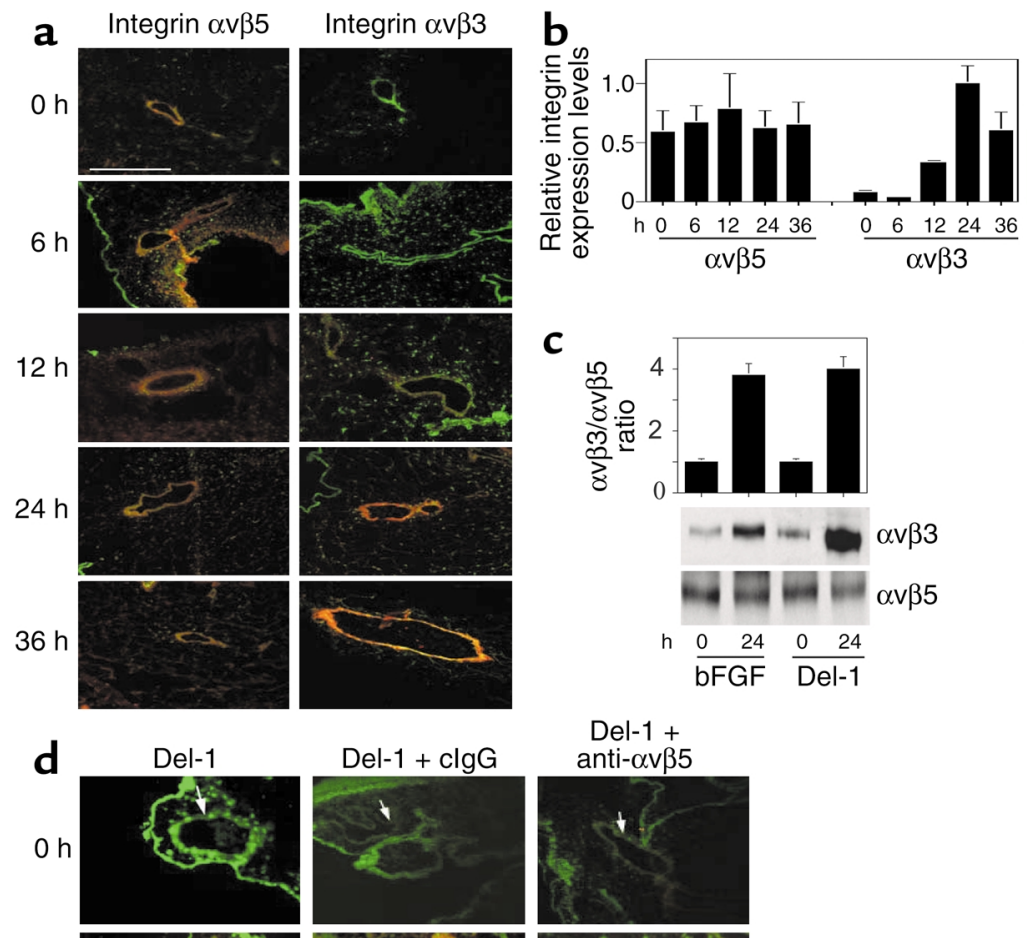

Del-1 +

anti- $\alpha v \beta 5$
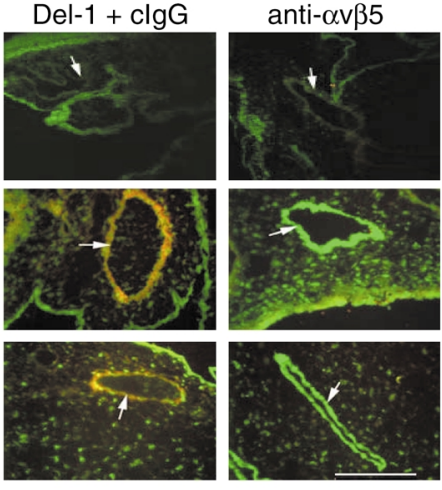

$12 \mathrm{~h}$

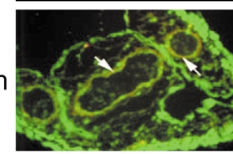

$48 \mathrm{~h}$
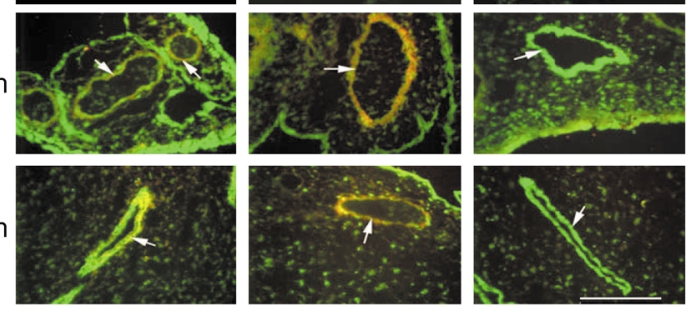

e

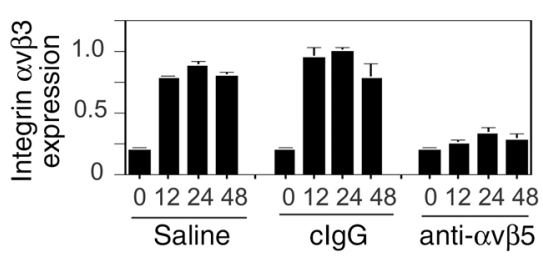



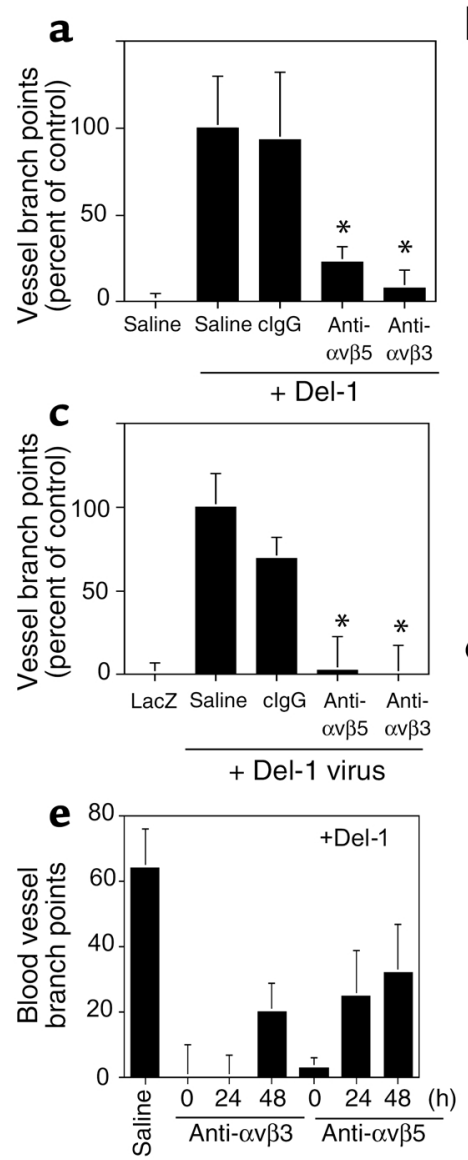

b

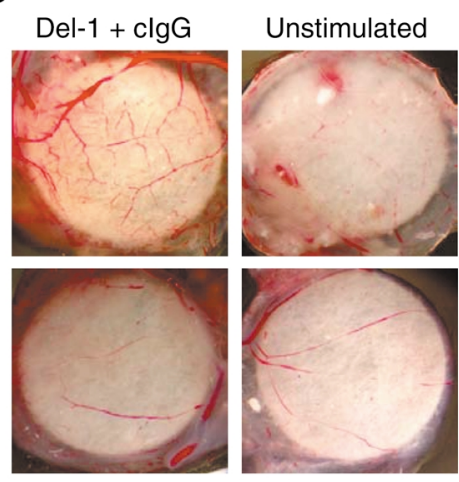

Del-1 + anti- $\alpha$ v $\beta 3$ Del-1 + anti- $\alpha \mathrm{v} \beta 5$
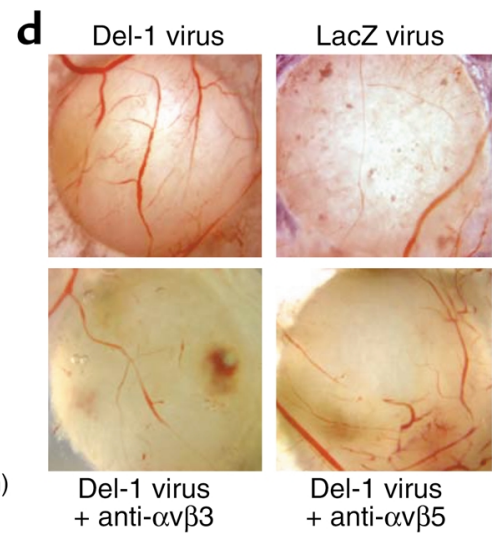

\section{Figure 5}

Del-1-mediated angiogenesis requires integrins $\alpha v \beta 3$ and $\alpha v \beta 5$. (a and b) Del-1-stimulated chick CAMs were treated with saline, anti- $\alpha v \beta 3$, anti- $\alpha v \beta 5$, or control IgG (W6/32), and blood vessel branch points were counted (a) or photographed at $\times 10$ magnification (b). Ten replicate embryos were tested per treatment group. (c and $\mathbf{d}$ ) CAMs were treated with $10^{7} \mathrm{PFU}$ of Del- 1 or $\beta$-galactosidase (LacZ) expressing adenovirus, and blood vessel branch points were counted (c) or photographed at $\times 10$ magnification (d). (e) Del-1-stimulated chick CAMs were treated with saline, anti- $\alpha v \beta 3$, anti- $\alpha v \beta 5$, or control IgG $(\mathrm{W} 6 / 32)$ at 0,24 , and 48 hours. Blood vessel branch points were counted. Ten replicate embryos were tested per treatment group. Asterisks indicate statistically significant result relative to Del-1 stimulation $(P<0.01)$.

integrins $\alpha v \beta 5$ and $\alpha v \beta 3$ during angiogenesis using the CAM model by performing immunohistochemical analysis of integrin expression in CAMs before and after Del-1 stimulation. We used the CAM rather than a murine model because immunological reagents for these integrins cross-react with chicken but not murine tissues. The temporal expression patterns of integrins $\alpha v \beta 5$ and $\alpha v \beta 3$ are distinct during Del-1-mediated angiogenesis. Integrin $\alpha v \beta 5$ is expressed at moderate levels on blood vessels in unstimulated CAMs, and its expression remains

(as determined by FACS analysis; Figure 3e) adhere to Del-1 and to vitronectin (Figure 3f). Adhesion to both proteins can be inhibited completely by function-blocking $A b$ 's directed against $\alpha v \beta 5$ (Figure $3 \mathrm{f}$ ), but not by isotype-matched $A b$ 's against $\alpha v \beta 3$ or $\alpha 5 \beta 1$ integrins. Thus, $\alpha v \beta 5$ is a cellular receptor for Del-1. To determine if $\alpha v \beta 5$ is a receptor for Del- 1 on ECs, we examined the adhesion of HUVECs to Del-1. HUVECs express $\alpha v \beta 5$ and $\alpha v \beta 3$ in a ratio of 1:4 (Figure $3 \mathrm{~g}$ ). HUVEC attachment to either Del-1 or vitronectin was blocked by anti$\alpha v \beta 5$ and $\alpha v \beta 3$ Ab's, but not by anti- $\alpha 5 \beta 1 \mathrm{Ab}$ 's (Figure $3 \mathrm{~h})$. HUVEC adhesion to and migration on Del- 1 is $70 \%$ $\alpha v \beta 3$ dependent and $30 \% \alpha v \beta 5$ dependent, in proportion to the relative levels of expression of these two integrins on HUVECs. Additionally, $\alpha v \beta 5$ serves as a functional receptor for Del-1 on microvascular ECs, the cells that are generally thought to participate in angiogenesis. Integrin $\alpha v \beta 3$ and $\alpha v \beta 5$ are expressed at equivalent levels on human microvascular ECs (HMVECs) (Figure 3i). Both receptors mediate cell attachment to Del-1 and vitronectin (Figure 3j). Blocking both receptors inhibits essentially all cell attachment to these matrix proteins. Thus, $\alpha v \beta 5$ is a functional cell surface receptor for Del-1 on ECs.

Integrin Del-1- $\alpha v \beta 5$ interactions induce integrin $\alpha v \beta 3$ expression and function. Because integrin $\alpha v \beta 5$ is a receptor for Del-1, it may play a role in Del-1-mediated angiogenesis. We examined the relative expression of unchanged on the vascular endothelium in CAMs after angiogenesis induction by Del-1 (Figure 4, a-c), whether analyzed by immunohistochemistry (Figure 4, $a$ and $b$ ) or by Western blot analysis (Figure 4c). In contrast, $\alpha v \beta 5$ is first expressed at 12 hours and peaks at 24-36 hours after stimulation by Del-1 (Figure 4, a-c), as has been observed for bFGF-stimulated CAMs (14, 15). Similar results are observed by either immunohistochemical or Western blot analysis. Our studies demonstrate that Del-1, like angiogenic growth factors, induces the de novo expression of $\alpha v \beta 3$ in vivo. These results also suggest that $\alpha v \beta 5$ could play a role in the initiation of Del-1-mediated angiogenesis because it is constitutively expressed; it may anchor Del-1 to the surface of quiescent vascular endothelium.

To evaluate the role of $\alpha v \beta 5$ in Del- 1 induction of $\alpha v \beta 3$ expression, we treated Del-1-stimulated CAMs with saline, $\alpha v \beta 5$ function-blocking $\mathrm{mAb}(\mathrm{P} 1 \mathrm{~F} 6)$, or isotypematched control $\mathrm{Ab}$ 's prior to performing immunohistochemical analysis for $\alpha v \beta 3$ expression. Anti- $\alpha v \beta 5$ Ab's inhibited $\alpha v \beta 3$ expression on CAMs $80 \%$ (Figure 4 , $d$ and e). These results show that $\alpha v \beta 5$ is required for Del-1mediated induction of $E C \alpha v \beta 3$ expression.

We further investigated the roles of $\alpha \mathrm{v}$ integrins in Del-1-mediated angiogenesis by testing the effects of function-blocking Ab's to both $\alpha v$ integrins in CAM angiogenesis assays. Both anti- $\alpha v \beta 3$ and $\alpha v \beta 5$ Ab's inhibited Del-1-induced angiogenesis at least $85 \%$ 
$(P<0.01)$, whether we applied purified recombinant Del-1 protein (Figure 5, a and b) or Del-1-expressing adenovirus (Figure 5, c and d) to CAMs. We hypothesized that if $\alpha v \beta 5$ is required to induce $\alpha v \beta 3$ expression during Del-1-mediated angiogenesis, then $\alpha v \beta 5$ regulates the early, but not the later phases, of Del-1mediated angiogenesis. In fact, $\alpha v \beta 5$ Ab's more potently inhibit Del-1-mediated angiogenesis when applied early (at 0 hours) rather than late (24-48 hours) during angiogenesis (Figure $5 \mathrm{e}$ ). In contrast, $\alpha v \beta 3$ plays a later role in Del-1-mediated angiogenesis, because it is not significantly expressed until 12-24 hours after stimulation (Figure 4, a-c). Furthermore, unlike $\alpha v \beta 5$ Ab's, $\alpha v \beta 3$ function-blocking $\mathrm{Ab}$ 's inhibited angiogenesis even if applied as late as 24 hours after angiogenesis initiation (Figure 5e). Because the in ovo chick embryo model of angiogenesis is a closed system, Ab's cannot be removed from the system once they enter it. Thus, anti- $\alpha v \beta 3$ Ab's applied at 0 hours remain in the circulation and inhibit angiogenesis even though $\alpha v \beta 3$ is expressed only after 24 hours of stimulation. These results indicate that both $\alpha v \beta 3$ and $\alpha v \beta 5$ play important roles in Del-1-induced angiogenesis, although at different time points.

To determine if $\alpha v \beta 5$ and $\alpha v \beta 3$ expression are required to promote Del-1-induced angiogenesis, we evaluated the ability of Del-1 and bFGF to induce angiogenesis in integrin $\beta 5$-null mice and in integrin $\beta 3$-null mice (16). These mice exhibit apparently normal angiogenesis during development (16). The bFGF induced an increase in CD31-positive vascular structures to the same extent in $\beta 5^{-/-}$mice $(n=10)$ as it did in age-matched sibling $\beta 5^{+/-}$mice $(n=3)$ and in wildtype $\beta 5^{+/+}$mice $(n=5)$ (Figure 6 , a and b). While Del-1 induced significant angiogenesis in $\beta 5^{+/-}(n=3)$ and $\beta 5^{+/+}(n=5)$ mice, however, it was substantially less effective in inducing angiogenesis in $\beta 5^{-/}$mice $(n=10$; $P<0.0001$; Figure 6, a and b). Interestingly, bFGF induced angiogenesis in $\beta 3^{-/-}$mice $(n=11)$ to approximately the same extent as it did in age-matched $\mathrm{F}_{2}$ $\beta 3^{+/+}$hybrid mice of the same genetic background $($ C57BL6 $\times 129 \mathrm{SF} 2 / \mathrm{J})(n=6)$ and in wild-type C57BL/6J $\mathrm{B3}^{+/+}$mice $(n=8)$ (Figure 6 , c and d); however, while Del-1 induced significant angiogenesis in C57BL6 and $\mathrm{F}_{2}$ hybrid $\beta 3^{+/+}$mice, it was ineffective in inducing angiogenesis in $\beta 3^{-/-}$mice $(n=11 ; P<0.0001)$. Taken together, these studies indicate that expression of integrin $\alpha v \beta 5$ as well as integrin $\alpha v \beta 3$ is required for Del-1-mediated angiogenesis.

Del-1- $\alpha \nu \beta 5$ interaction regulates HOX gene expression. Some angiogenic growth factors, such as bFGF, induce EC expression of the Hox D3 homeobox gene, which in turn converts ECs from the resting to the angiogenic state, in part by upregulating expression of the $\beta 3$ inte-
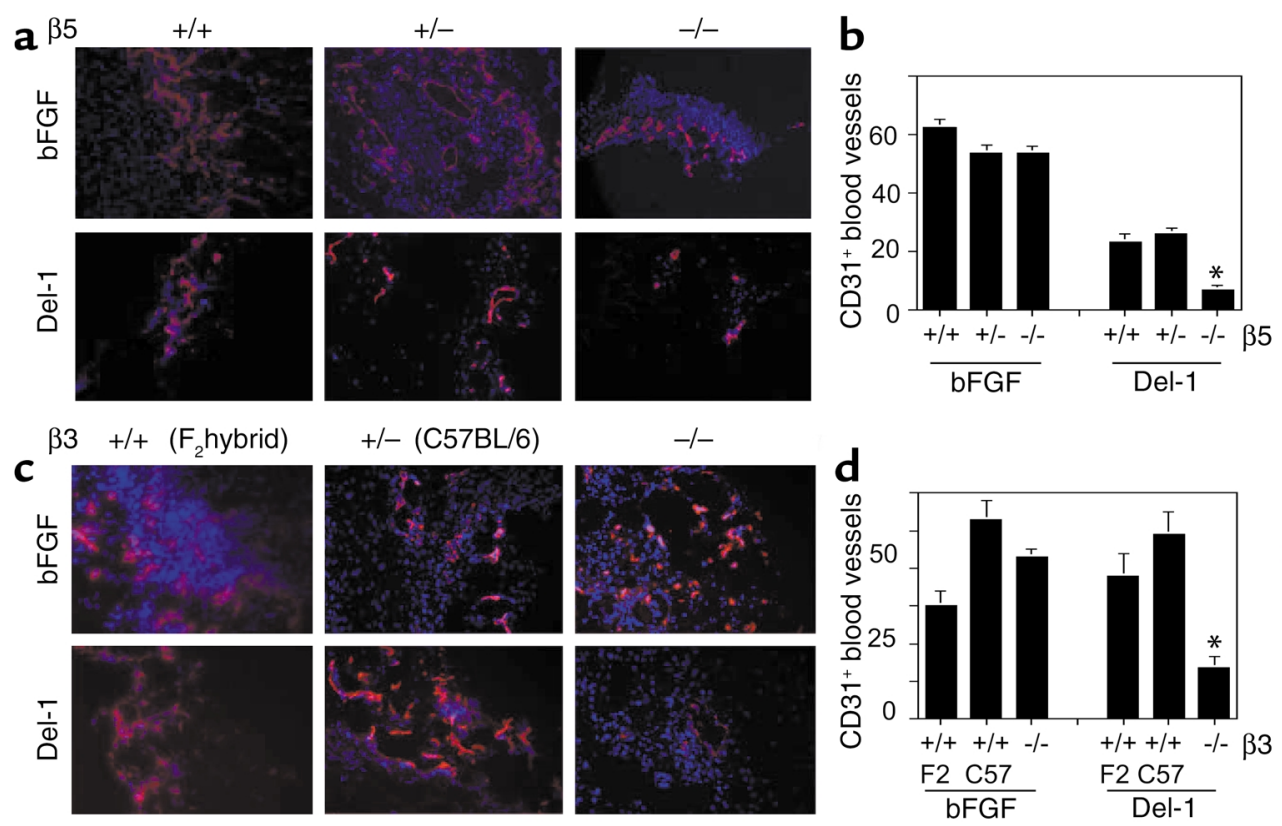

\section{Figure 6}

Integrin $\alpha v \beta 5$ is required for Del-1- but not bFGF-mediated angiogenesis. (a) Angiogenesis was induced by injection of growth factor-reduced Matrigel containing bFGF or Del- 1 in homozygous integrin $\beta 5$-null $\left(\beta 5^{-/-}\right)$mice and age-matched heterozygous $\left(\beta 5^{+-}\right)$sibling mice as well as $\beta 5^{+/+}$mice. Cryosections of Matrigel plugs were immunostained with Ab's directed against murine CD31. (b) CD31-positive vessels were quantified in five $\times 200$ microscopic fields per plug, and the mean \pm SEM for each treatment group was determined. Asterisk indicates statistically significant result relative to wild-type controls $(P<0.001)$. (c) Angiogenesis was induced by injection of growth factor-reduced Matrigel containing bFGF or Del- 1 in homozygous integrin $\beta 3$-null $\left(\beta 3^{-/-}\right)$mice, age- and strain-matched $C 57 \mathrm{BL} / 6 \times 129 \mathrm{~S} \mathrm{~F}_{2}$ hybrid $\beta 3$-positive mice $\left(F_{2}\right)$, as well as age-matched $\beta 3$-positive C57BL/ 6 mice (C57). Cryosections of Matrigel plugs were immunostained with Ab's directed against murine CD31. (d) CD31-positive vessels were quantified in five $\times 200$ microscopic fields per plug and the mean $\times$ SEM for each treatment group was determined. Asterisk indicates statistically significant result relative to wild-type controls $(P<0.001)$. 

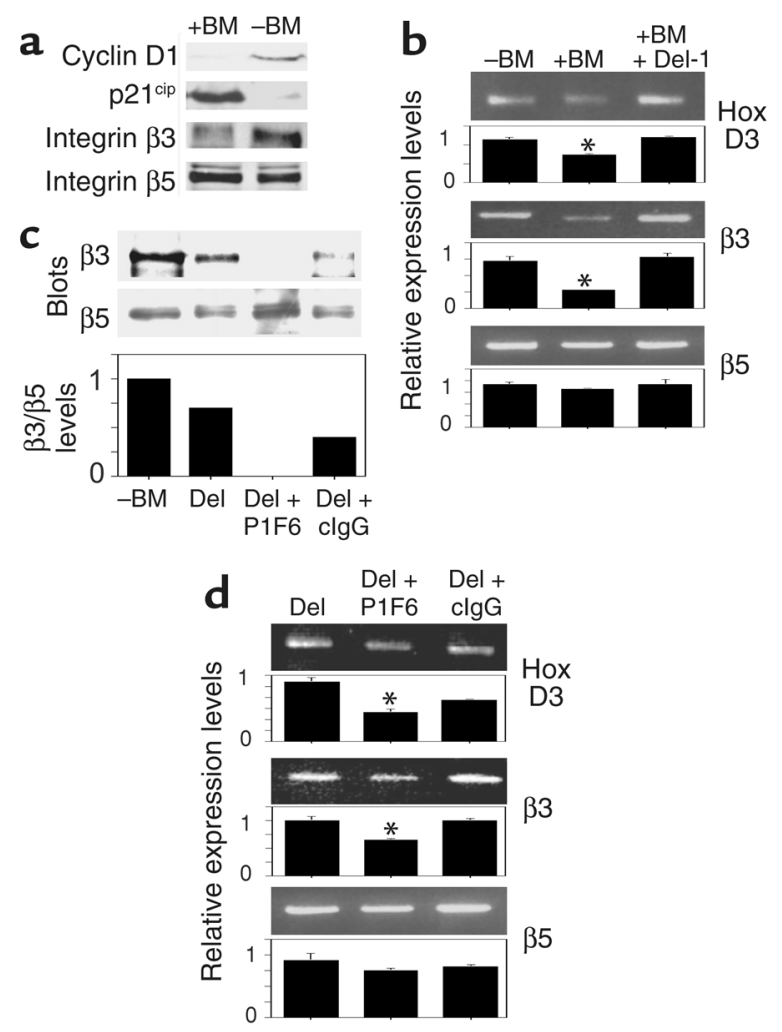

grin subunit and urokinase plasminogen activator (24). Therefore, we examined the possibility that the $\alpha v \beta 5-D e l-1$ interaction regulates Hox D3 transcription and, thereby, $\alpha v \beta 3$ expression. To examine the regulation of Hox D3 and $\alpha v \beta 3$ expression by Del-1 in vitro, we used ECs that express lower levels of $\alpha v \beta 3$. Since ECs in culture express significant levels of $\alpha v \beta 3$, ECs were plated on layers of basement membrane (growth factor-reduced Matrigel) composed of collagen, laminin, and proteoglycans to induce withdrawal from the cell cycle and suppress $\alpha v \beta 3$ expression (24-29). As they withdraw from the cell cycle, ECs on basement membrane express less cyclin D1, but more cell cycle inhibitor, $\mathrm{p} 21^{\mathrm{cip}}$, than proliferating ECs, indicating that the cells have withdrawn from the cell cycle (Figure 7a). ECs on basement membrane also show reduced integrin $\alpha v \beta 3$ protein (Figure $7 \mathrm{a}$ ) and reduced integrin $\beta 3$ and Hox D3 message expression (Figure 7b). Hox D3 message levels were reduced $50 \%$, whereas $\beta 3$ message levels were reduced $75 \%$. Addition of Del-1 to these cultures, however, suppresses differentiation and increases gene expression of integrin $\beta 3$ and $H_{0 x} D 3$ (Figure $7 \mathrm{~b} ; P<0.015)$, indicating that Del-1 suppresses withdrawal of ECs from the cell cycle. These studies therefore indicate that Del-1 stimulates expression of HoxD3 and $\alpha v \beta 3$ in ECs.

To determine whether Hox D3 gene expression depends on $\alpha v \beta 5-$ Del-1 interactions, we added function-blocking anti- $\alpha v \beta 5$ Ab's to Del-1-stimulated EC basement membrane cultures. These Ab's significantly reduced $\beta 3$ protein expression (Figure $7 c ; P<0.01$ ) and inhibited Hox D3 and integrin $\beta 3$ gene expression

\section{Figure 7}

Del-1- $\alpha v \beta 5$ interactions induce Hox D3 expression. (a) ECs were plated in monolayers (-BM) or on tissue-culture plates coated with thin layers of basement membrane (+BM) prior to cell lysis and Western blot analysis for cyclin D1, p21cip, and integrins $\beta 3$ and $\beta 5$. (b) RT-PCR was performed for Hox D3, integrins $\beta 3$ and $\beta 5$, and GADPH (not shown). Relative levels of each PCR product were determined by densitometry in comparison with GADPH expression levels for each treatment. Asterisks indicate statistical significance relative to monolayer culture $(-\mathrm{BM})(P<0.02)$. (c) ECs were plated on endothelial monolayers in serum culture, BM + Del-1 (Del), or on BM + Del-1 with anti- $\alpha v \beta 5$ function-blocking Ab's (Del + P1F6), or control Ab's (Del + clgG). Integrin $\beta 5$ and $\beta 5$ protein expression levels were determined by Western blot analysis. Average expression levels for each integrin were determined in three experiments by densitometry. (d) RT-PCR was performed on RNA isolated from cells treated as in $\mathbf{c}$ for Hox $D 3$, integrins $\beta 3$ and $\beta 5$, and GADPH. Relative levels of each PCR product were determined by densitometry in comparison with $G A D P H$ expression levels for each treatment. Asterisks indicate statistical significance relative to Del-1 stimulation $(P<0.02)$.

$25-50 \%$ (Figure $7 \mathrm{~d} ; P<0.02$ ). These studies indicate that $\alpha v \beta 5$ recognition of Del- 1 is required to trigger conversion of the EC to the proliferative state. In contrast, vitronectin, another $\alpha v \beta 5$ ligand, does not have a similar effect (not shown). Thus, integrin $\alpha v \beta 5$ specifically regulates the EC response to the proangiogenic protein Del-1.

To determine whether Hox D3 is required for Del-1mediated angiogenesis, we evaluated the effects of Hox D3 antisense on angiogenesis in the CAM. Because human and chicken Hox D3 genes are highly conserved, with overall DNA sequence identity of $83 \%$, human Hox D3 sense and anti-sense constructs (24) were applied to CAMs stimulated by bFGF or Del-1. Direct application of DNA to CAMs results in significant gene expression in proliferating cells such as ECs (30). Expression of the Hox D3 antisense, but not sense, construct in chick CAMs significantly blocked angiogenesis induced by bFGF and Del-1 (Figure 8a; $P<0.01$ ). Chicken Hox D3 gene expression was induced by bFGF and Del-1, but was significantly blocked by Hox D3 antisense constructs, indicating that the antisense had inhibited expression of the chick Hox D3 gene (Figure 8, b and c). Expression of chicken and human Hox D3 in the CAM was quantified by RT-PCR (Figure 8, b and d), while GFP expression was verified by Western blot analysis of CAM lysates (Figure 8e). Hox D3 antisense suppressed integrin $\beta 3$ but not $\beta 5$ expression in both bFGF- and Del-1-stimulated CAMs (Figure 8e). These studies indicate that Del-1-mediated angiogenesis requires activation of an angiogenic program that leads to Hox D3 expression and subsequently to $\alpha v \beta 3$ expression. 


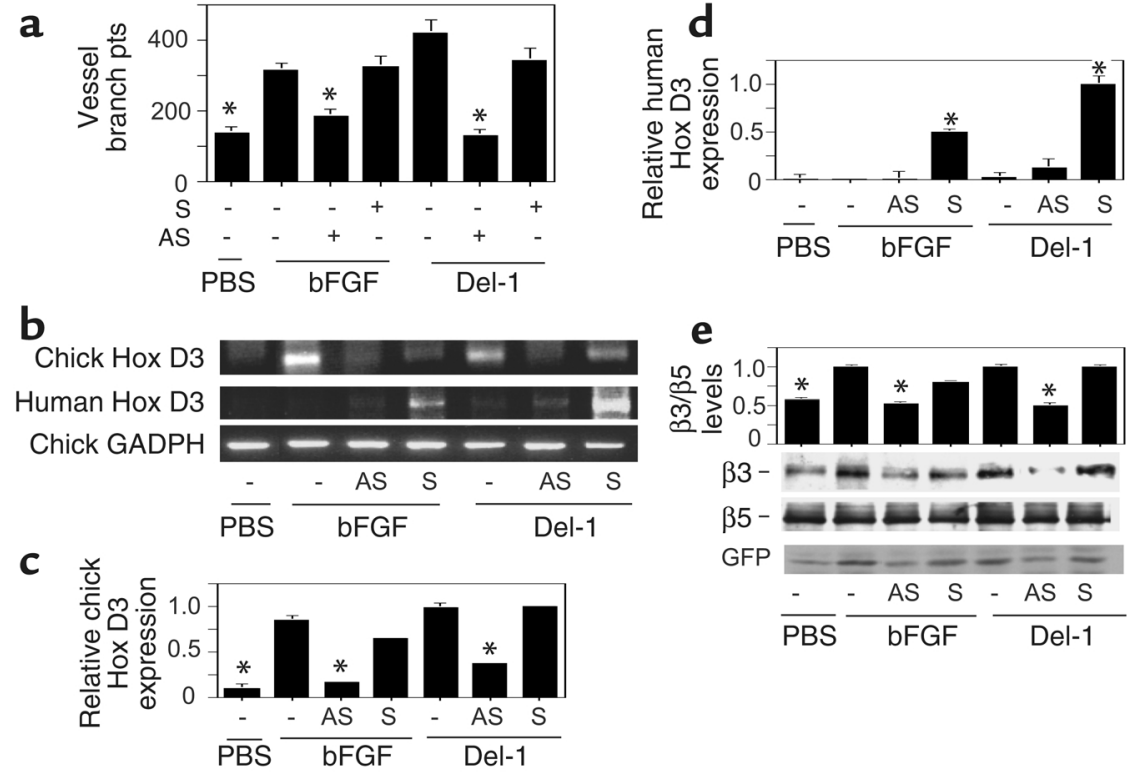

Figure 8

Hox D3 is required for Del-1-induced angiogenesis. (a) CAMs of 10-day-old chicken embryos stimulated by PBS, bFGF, or Del-1 were transfected with either N1-GFP reporter vector or Hox D3 sense (S), or Hox D3 antisense (AS) DNA expression constructs and N1-GFP. CAMs were fixed prior to excision, and blood vessel branch points (vessel branch pts) were quantified. (b) Expression levels of the chicken (chick) Hox D3, human Hox D3, and chicken GADPH genes in treated CAM tissues were determined by RT-PCR. (c and d) Relative levels of chick Hox D3 (c) and human Hox D3 (d). PCR products were determined by densitometry in comparison with GADPH expression levels for each treatment. (e) Expression levels of integrin $\beta 3$ and $\beta 5$, as well as GFP in CAMs stimulated with Del-1 or bFGF and treated with saline (PBS), Hox D3 antisense or sense were determined by Western blot analysis. Average expression levels for each integrin were determined in three separate experiments by densitometry. Asterisks indicate statistical significance relative to bFGF or Del-1 stimulation $(P<0.01)$.

Overexpression of Hox D3 promotes vascular proliferation and leads to hemangioma formation in CAMs (23). To determine whether $\alpha v \beta 5$ function is required once Hox D3 is expressed, we transduced CAMs with Hox D3 and negative control retroviruses in the presence or absence of $\alpha v \beta 5$ or $\alpha v \beta 3$ antagonists. Hox D3 transduction induced a hemangioma-like angiogenic response in the CAM that was completely blocked by Ab's directed against integrin $\alpha v \beta 3(P<0.01$; Figure 9, a and $b)$. In contrast, anti- $\alpha v \beta 5 \mathrm{Ab}$ 's had no effect on the Hox D3-induced angiogenesis (Figure 9, a and b). Control viruses did not induce hemangiomas in the CAM (Figure 9, $\mathrm{a}$ and $\mathrm{b}$ ). Taken together, these results demonstrate that Del-1- $\alpha v \beta 5$ interactions regulate Hox D3

\section{Figure 9}

Hox D3 is downstream of $\alpha v \beta 5$ but upstream of $\alpha v \beta 3$. (a) Q4dh cells transfected with Hox D3 expressing control virus (neg cntl) retroviral constructs were cultured on replicate CAMs in the presence of saline (HOX D3 virus), anti- $\alpha v \beta 3$ (Hox D3 + LM609), anti- $\alpha v \beta 5$ (Hox D3 + P1F6), or control IgG (W6/32, not shown). CAMs were excised after fixation, and representative CAMs were photographed. Each treatment group contained ten to 12 replicate CAMs. (b) Blood vessel branch points on filter disks were quantified and graphed as mean \pm SEM. Asterisks indicate statistical significance relative to Hox D3 virus stimulation $(P<0.01)$. expression and that Hox D3 then regulates $\alpha v \beta 3$ expression and function during angiogenesis.

Taken together, these results demonstrate that Del-1 stimulates angiogenesis by binding to quiescent EC integrin $\alpha \mathrm{v} \beta 5$, thereby inducing Hox D3-regulated expression of integrin $\alpha v \beta 3$. These studies delineate a novel angiogenesis pathway induced by the ECM protein Del-1.

\section{Discussion}

The studies presented here indicate that the angiogenic protein, Del-1, regulates a complex pathway of angiogenesis that can result in beneficial angiogenesis in response to ischemia. Integrin $\alpha v \beta 5$ on resting endothelium binds Del-1 and triggers a program leading to EC activation and expression of the Hox D3 homeobox gene and, subsequently, integrin $\alpha v \beta 3$.

Our studies show that Del-1$\alpha v \beta 5$ interactions induce $\alpha v \beta 3$ expression and promote the angiogenic phenotype in vitro and in vivo. Basement membrane cultures were used in these studies to evaluate the role of Del- 1 in the regulation of Hox D3 and $\alpha v \beta 3$ expression in vitro. In vivo, quiescent ECs can be stimulated to undergo angiogenesis by various growth factors and by the angiomatrix protein Del-1. ECs begin to proliferate, upregulate cyclin D1, and express $\alpha v \beta 3$. Upon completion of angiogenesis, endothelial tubes are formed, and expression of cyclin D1 and $\alpha v \beta 3$ are

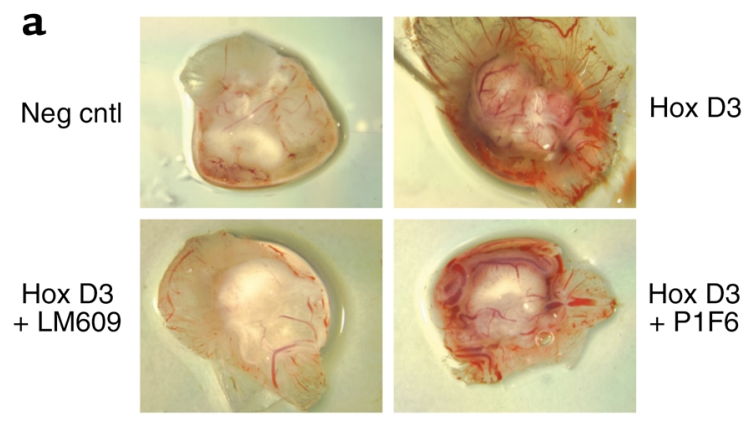

b

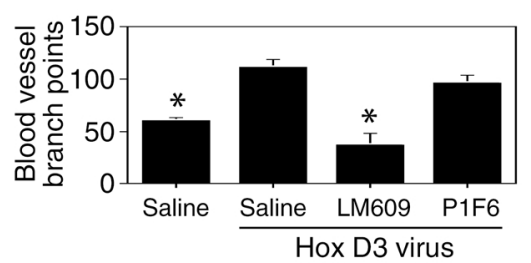


downregulated. Thin layers of basement membrane (growth factor-reduced Matrigel) composed of collagen, laminin, and proteoglycans were used in this study to force ECs into a differentiated state in vitro, allowing us to examine the effect of Del-1 on nonproliferative, differentiated ECs that express low levels of integrin $\alpha v \beta 3$. In vitro basement membrane cultures cause withdrawal from the cell cycle and suppression of $\alpha v \beta 3(24,25)$. Our studies indicate that Del-1 interaction with $\alpha v \beta 5$ stimulates EC Hox $\mathrm{D} 3$ and $\alpha v \beta 3$ expression in vitro and in vivo. Our in vivo studies indicate that these proteins are required for Del-1-mediated angiogenesis.

The studies presented here indicate that Del-1induced angiogenesis depends upon integrins $\alpha v \beta 5$ and $\alpha v \beta 3$ because genetic deletion of either integrin, as well as antagonists of these integrins, inhibit Del-1mediated angiogenesis. Mice lacking integrins $\alpha v \beta 5$ and $\alpha v \beta 3$ exhibit embryonic and adult angiogenesis, suggesting that these integrins are not required for some forms of embryonic and tumor-induced angiogenesis $(31,32)$. These studies are in apparent conflict with studies indicating that $\alpha v \beta 3$ integrin ligation is required to provide survival signals to proliferating ECs during angiogenesis in vivo in normal animals $(14,15$, $33,34)$. Such studies have shown that when expressed, $\alpha v \beta 3$ must be ligated or cell death is induced by a caspase 8-dependent process termed integrin-mediated death $(33,34)$. Mice lacking $\alpha v \beta 3$ exhibit enhanced tumor angiogenesis (31), possibly because a key "death receptor" is absent $(33,34)$. Our studies indicate, however, that $\alpha v \beta 5$ and $\alpha v \beta 3$ are required for Del-1-mediated angiogenesis because Del-1-induced angiogenesis does not occur in the genetic absence of either integrin.

While Del-1 angiogenesis depends upon integrin $\alpha v \beta 3$ function in genetically normal animals, it is not clear if Del-1 itself serves as a ligand for $\alpha v \beta 3$ during angiogenesis. In vitro studies indicate that Del-1 is a ligand for $\alpha v \beta 3$ and that it and $\alpha v \beta 3$ are coordinately expressed in association with angiogenic blood vessels. It is possible that Del-1 may regulate angiogenesis by binding first to $\alpha v \beta 5$ and then to $\alpha v \beta 3$ or that Del-1 may also regulate the expression or generation by proteolysis of additional $\alpha v \beta 3$ ligands.

Because Del-1 and a few other novel ECM proteins, but not all ECM proteins, induce angiogenesis, it is possible that these proteins also interact directly with growth factor receptors as well as integrins. Such interactions could account for the differential effect of the $\alpha v \beta 5$ ligands Del- 1 and vitronectin in angiogenesis models. While both matrix proteins mediate $\alpha v \beta 5$ dependent adhesion and migration, only Del-1 induces EC proliferation and angiogenesis. Del-1 may exert EC-specific activities by binding to receptors found on ECs and not on other cells. For example, Del1 does not promote HT29 colon carcinoma cell proliferation, nor does it upregulate integrin $\beta 3$ or Hox D3 expression in these cells (data not shown), in contrast to its effects on ECs. Additionally, it is possible that
Del-1 binding to EC integrins induces expression of proangiogenic growth factors. To understand how Del-1 regulates angiogenesis, it will be important to delineate the difference in signal transduction induced by this and other ECM proteins.

A proangiogenic ECM protein may play an important role during localized embryonic and pathological angiogenesis. The local deposition of Del-1 could allow locally controlled vascular proliferation. Once in the extracellular space, Del-1 may associate with other ECM proteins, providing a scaffold upon which ECs migrate during angiogenesis.

We have identified a novel mechanism that accounts for the induction of neovascularization by Del-1 and perhaps other proangiogenic ECM proteins. Del-1 ligation of integrin $\alpha v \beta 5$ induces Hox D3 expression, thereby promoting integrin $\alpha v \beta 3$ expression and function and the invasion and growth of new blood vessels. Del-1 thus regulates a program of angiogenesis characterized by expression and function of the transcription factor Hox D3. As a proangiogenic factor that promotes recovery from ischemic injury, Del-1 may be a useful tool for the management of ischemic diseases.

\section{Acknowledgments}

This work was supported by grants from the National Cancer Institute (CA71619 and CA83133) to J.A. Varner and by a grant from the National Heart Lung and Blood Institute to T. Quertermous (NHLB52168). We would like to thank Richard Hynes for the $\beta 3$-null mice; Dean Sheppard for the generous gift of integrin $\beta 5^{+/-}$and $\beta 5^{-/-}$mice; and David Cheresh, Mark Ginsberg, and Glen Nemerow for gifts of Ab's and purified integrins. We would like to thank Eric Rabinovsky for assistance with the rabbit model of the hind limb. We would also like to thank Yuhong Zhu, Hong Yin, Gaylen Howell, Elizabeth Wilson, Mary Thiesse, Jijun Wang, Isaac Van Sligtenhorst, and Wendy Nelson for excellent technical assistance.

1. Varner, J. 1997. The role of vascular cell integrins $\alpha v \beta 3$ and $\alpha v \beta 5$ in angiogenesis. In Regulation of Angiogenesis. I. Goldberg and E.M. Rosen, editors. Birkhauser Verlag. Basel, Switzerland. 361-390.

2. Carmeliet, P., and Jain, R.K. 2000. Angiogenesis in cancer and disease. Nature. 407:249-257.

3. Eliceiri, B.P., and Cheresh, D.A. 1999. The role of $\alpha v$ integrins during angiogenesis: insights into potential mechanisms of action and clinical development. J. Clin. Invest. 103:1227-1230.

4. Yancopoulos, G.D., et al. 2000. Vascular-specific growth factors and blood vessel formation. Nature. 407:242-248.

5. Baumgartner, I., et al. 1998. Constitutive expression of VEGF 165 following intramuscular gene transfer promotes collateral vessel development in patients with critical limb ischemia. Circulation. 97:1114-1123.

6. Banai, S., et al. 1994. Angiogenic-induced enhancement of collateral blood flow to ischemic myocardium by vascular endothelial growth factor in dogs. Circulation. 89:2183-2189.

7. Asahara, T., et al. 1999. VEGF contributes to postnatal neovascularization by mobilizing bone marrow derived endothelial progenitor cells. EMBO J. 18:3964-3972.

8. Babic, A.M., Kireeva, M.L., Kolesnikova, T.V., and Lau, L.F. 1998. Cyr 61, a product of growth-factor inducible immediate early gene, promotes angiogenesis and tumor growth. Proc. Natl. Acad. Sci. U. S. A. 95:6355-6360.

9. Babic, A.M., Chen C.-C., and Lau, L.F. 1999. Fisp12/mouse connective tissue growth factor mediates endothelial cell adhesion and migration through integrin $\alpha v \beta 3$, promotes endothelial cell survival and induces angiogenesis in vivo. Mol. Cell. Biol. 19:2958-2966. 
10. Kireeva, M.L., Lam, S.C.-T., and Lau, L.F. 1998. Adhesion of human umbilical vein endothelial cells to the immediate early gene product Cyr61 is mediated through integrin $\alpha v \beta 3$. J. Biol. Chem. 273:3090-3096.

11. Penta, K., et al. 1999. Del-1 induces integrin signaling and angiogenesis by ligation of $\alpha v \beta 3$. J. Biol. Chem. 274:11101-11109.

12. Aoka, Y., et al. 2002. The embryonic angiogenic factor Del 1 accelerates tumor growth by enhancing vascular formation. Microvasc. Res. 64:148-161.

13. Hidai, C., et al. 1998. Cloning and characterization of developmental endothelial locus-1: an embryonic endothelial cell protein that binds the $\alpha v \beta 3$ integrin receptor. Genes Dev. 12:21-33.

14. Brooks, P.C., et al. 1994. Integrin $\alpha v \beta 3$ antagonists promote tumor regression by inducing apoptosis of angiogenic blood vessels. Cell. 7:1157-1164.

15. Eliceiri, B.P., Klemke, R., Stromblad, S., and Cheresh, D.A. 1998. Integrin $\alpha v \beta 3$ requirement for sustained mitogen-activated protein kinase activity during angiogenesis. J. Cell Biol. 140:1255-1263.

16. Huang, X., Griffiths, M., Wu, J., Farese, R.V., Jr., and Sheppard, D. 2000. Normal development, wound healing, and adenovirus susceptibility in beta5-deficient mice. Mol. Cell. Biol. 20:755-759.

17. Eliceiri, B.P., et al. 1999. Selective requirement for Src kinases during VEGFinduced angiogenesis and vascular permeability. Mol. Cell. 4:915-924.

18. Wang, J., Wilson, E., Van Sligtenhorst, I., Fix, M., and Coleman, M. 2001. In vivo gene expression in muscle using a polymer delivery system. Mol. Ther. 3:S65. (Abstr.)

19. Hartikka, J., et al. 2001. Electroporation-facilitated delivery of plasmid DNA in skeletal muscle: plasmid dependence of muscle damage and effect of poloxamer 188. Mol. Ther. 4:407-415.

20. Takeshita, S., et al. 1994. Therapeutic angiogenesis. A single intraarterial bolus of vascular endothelial growth factor augments revascularization in a rabbit ischemic hind limb model. J. Clin. Invest. 93:662-670.

21. Yatohgo, T., Izumi, M., Kashiwagi, H., and Hayashi, M. 1988. Novel purification of vitronectin from human plasma by heparin affinity chromatography. Cell Struct. Funct. 13:281-292.

22. Kim, S., Harris, M., and Varner, J. 2000. Regulation of angiogenesis in vivo by ligation of integrin $\alpha 5 \beta 1$ with the central cell binding domain of fibronectin. Am. J. Pathol. 156:1345-1362.

23. Orlando, R.A., and Cheresh, D.A. 1991. Arginine-glycine-aspartic acid binding leading to molecular stabilization between integrin $\alpha v \beta 3$ and its ligand. J. Biol. Chem. 266:19543-19550.

24. Boudreau, N., Andrews, C., Srebow, A., Ravanpay, A., and Cheresh, D.A. 1997. Induction of the angiogenic phenotype by Hox D3. J. Cell Biol. 139:257-264.

25. Myers, C., Charbonneau, A., and Boudreau, N. 2000. Homeobox B3 promotes capillary morphogenesis and angiogenesis. J. Cell Biol. 148:343-351.

26. Kubota, Y., Kleinman, H.K., Martin, G.R., and Lawley, T.J. 1988. Role of laminin and basement membrane in the morphological differentiation of human endothelial cells into capillary-like structures. J. Cell Biol. 107:1589-1598.

27. Boudreau, N., Werb, Z., and Bissell, M.J. 1996. Suppression of apoptosis by basement membrane requires three dimensional tissue organization and withdrawal from the cell cycle. Proc. Natl. Acad. Sci. U. S. A. 93:3509-3513.

28. Donovan, D., Brown, N.J., Bishop, E.T., and Lewis, C.E. 2001. Comparison of three in vitro human angiogenesis assays with capillaries formed in vivo. Angiogenesis. 4:113-121.

29. Feng, X., Clark, R.A.F., Galanakis, D., and Tonnesen, M.C. 1999. Fibrin and collagen differentially regulate human dermal microvascular cell integrins: stabilization of $\alpha \mathrm{v} \beta 3$ mRNA. J. Invest. Derm. 113:913-919.

30. Kim, S., Bakre, M., Yin, H., and Varner, J. 2002. Inhibition of endothelial cell survival and angiogenesis by protein kinase A. J. Clin. Invest. 110:933-941. doi:10.1172/JCI200214268.

31. Hodivala-Dilke, K.M., et al. 1999. $\beta 3$-integrin-deficient mice are a model for Glanzmann thrombasthenia showing placental defects and reduced survival. J. Clin. Invest. 103:229-238.

32. Reynolds, L.E., et al. 2002. Enhanced pathological angiogenesis in mice lacking $\beta 3$ and $\beta 5$ integrins. Nature Med. 8:229-238.

33. Stupack, D.G., Puente, X.S., Butsaboualoy, S., Storgard, C.M., and Cheresh, D.A. 2001. Apoptosis of adherent cells by recruitment of caspase-8 to unligated integrins. J. Cell Biol. 155:459-470.

34. Cheresh, D.A., and Stupack, D.G. 2002. Integrin-mediated death: an explanation of the integrin-knockout phenotype? Nature Med. 8:1-2. 